BULLETIN Bulletin hispanique

HispaniQuE Université Michel de Montaigne Bordeaux

$116-2$ | 2014

Référentialité/autoréférentialité dans le roman espagnol contemporain : bilan et perspectives

\title{
Grandeza mexicana de Bernardo de Balbuena
}

¿una corografía de propaganda económica?

Jacques Joset

\section{OpenEdition}

\section{Journals}

\section{Edición electrónica}

URL: http://journals.openedition.org/bulletinhispanique/3617

DOI: 10.4000/bulletinhispanique.3617

ISBN: 979-10-300-0156-3

ISSN: 1775-3821

\section{Editor}

Presses universitaires de Bordeaux

\section{Edición impresa}

Fecha de publicación: 1 diciembre 2014

Paginación: 855-868

ISBN: 978-2-86781-963-6

ISSN: 0007-4640

Referencia electrónica

Jacques Joset, «Grandeza mexicana de Bernardo de Balbuena », Bulletin hispanique [En línea],

116-2 | 2014, Publicado el 01 diciembre 2017, consultado el 20 abril 2019. URL : http://

journals.openedition.org/bulletinhispanique/3617 ; DOI : 10.4000/bulletinhispanique.3617 


\title{
VARIÉTÉS
}

\section{Grandeza mexicana de Bernardo de Balbuena: ¿una corografía de propaganda económica?}

\author{
JACQUes JoseT \\ Université de Liège - Belgique
}

"Todo en este discurso está cifrado", dernier vers de l' "Argumento» et titre du dernier chapitre de Grandeza mexicana de Bernardo de Balbuena, renvoie essentiellement aux personnalités de l'entourage du roi d'Espagne, Philippe III, le comte de Lemos et le duc de Lerma, capables, de par leurs pouvoirs, d'encourager la politique d'émigration péninsulaire vers la Nouvelle Espagne, nouveau centre de l'Empire à l'époque de la première mondialisation transatlantique.

Mots-clés : Grandeza mexicana, Bernardo de Balbuena, destinataires, chorographie, mondialisation transatlantique.

"Todo en este discurso está cifrado", último verso del "Argumento» y título del último capitulo de Grandeza mexicana de Bernardo de Balbuena, remite por lo esencial a las personalidades más próximas al rey Felipe III, el conde de Lemos y el duque de Lerma, quienes por sus poderes en la Corte tenían la capacidad de fomentar la politica de emigración peninsular hacia la Nueva España, nuevo centro del Imperio en la época de la primera globalización trasatlántica.

Palabras claves: Grandeza mexicana, Bernardo de Balbuena, destinatarios, corografía, globalización trasatlántica.

"Todo en este discurso está cifrado", the last verse of the "Argumento» and the last chapter of Bernardo de Balbuena's Grandeza Mexicana primarily refers to people in the entourage of the King of Spain, Philip III, the Count of Lemos and the Duke of Lerma, able, by their power, to encourage peninsular emigration policy to the Nueva España, the new center of the Empire at the time of the first transatlantic globalization.

Keywords: Grandeza mexicana, Bernardo de Balbuena, addressees, chorographie, transatlantic globalization. 
$\mathrm{E}$ ste último verso de la octava real del "Argumento" de la "Carta del Bachiller Bernardo de Balbuena a la Señora Doña Isabel de Tobar y Guzmán, describiendo la famosa ciudad de México y sus grandezas»² agudizó la sagacidad de los hermeneutas de Grandeza mexicana, "épica urbana» ${ }^{3}$ del autor del Bernardo (1624), ejemplar destacado de épica clásica.

Huelga decir que en tanto cierre de estrofa el verso ya "compendia» tanto el "argumento" de Grandeza mexicana (1604) como toda la obra que sigue: cada capítulo lleva como título un verso del argumento menos el penúltimo que se bifurca para encabezar el séptimo ("Gobierno ilustre») y el octavo ("Religión y Estado») dando paso a un "epílogo y capítulo último», el noveno, titulado, como era de esperar, "Todo en este discurso está cifrado», especie de recopilación de todo lo anterior a la que se pega unas alabanzas algo pomposas a la madre patria.

Compendiar, recopilar, resumir son, de hecho, las palabras clave de la entrada Cifrar del Tesoro de la lengua castellana o española (1611), de siete años posteriores a la publicación de Grandeza mexicana, descripción hiperbólica de la capital de Nueva Espańa. Pero el mismo diccionario define Cifra como «escritura enigmática, con caracteres peregrinos o los nuestros trocados unos por otros, en valor o en lugar» ${ }^{4}$. Ni siquiera falta el significado "guarismo», palabra explícitamente mencionada en una interrogación retórica cuya respuesta no puede ser sino una hipérbole: "¿Quién podrá dar guarismo a tus riquezas, / número a tus famosos mercaderes [...]?» $(\mathrm{V}, 35 \mathrm{ab}, 205)$ o en la presentación no menos hiperbólica de la opulencia de las instituciones eclesiásticas:

Sus fundaciones, dotación y renta,

¿de qué guarismo compondrá la suma

por más letras y ceros que consienta? (VIII, 56, 232)

Así se completa la semántica plural de lo cifrado, buen ejemplo de barroquismo lingüístico que invita a descifrar lo que Balbuena quiso ocultar detrás de un discurso aparentemente llano como es el de cualquier corografía por estilísticamente inflada que sea.

Y los intentos de los buscadores de sentido se desparraman en todas las direcciones de las cuales mencionaré tan sólo un botón de muestras. Así Alfredo A. Roggiano, a la zaga de Octavio Paz, quien de Balbuena alaba «su

1. Balbuena (2011: 164). De aquí en adelante citaré Grandeza mexicana por esta edición de Asima F. X. Saad Maura. Modernizo la grafía, acentuación y puntuación de todos los textos antiguos citados. En las citas de los versos de Grandeza mexicana, la cifra romana remite al capítulo, la primera arábiga al terceto (o eventualmente cuarteta) dentro del capítulo y la segunda a la página de la edición de referencia.

2. Balbuena (2011: 164).

3. El término fue felizmente acuñado por Luis Adolfo Domínguez (1971: XV).

4. Covarrubias (2006: s. v.). 
inagotable fantasear, su amor a la palabra plena y resonante» ${ }^{5}$, cifró el discurso de Grandeza mexicana en su pura estructura poética: «Más que el tema del esplendor material, desarrollo de instituciones, tesoros artísticos y nobleza moral de la grandeza mexicana, [...] lo que resalta en cada verso es la decidida voluntad de componer una forma que sea válida como visión poética en sí.. ${ }^{6}$

En cambio, para Fernando Gómez, la estética supuestamente manierista de la obra es una cifra que supone la oralidad, "la declamación y la audiencia colectiva de una selección de fragmentos» para el círculo restringido de oidores formado por doña Isabel de Tobar y Guzmán y su entorno inmediato. ${ }^{7}$ A este artículo basado en la hipótesis "de centralidad auricular» (sic) no le faltan sin embargo intuiciones acertadas como la de un público -lector digo yo- elitista aunque no necesariamente reducido a los pocos criollos y recién llegados de la Península seleccionado aquí un tanto arbitrariamente.

Los mismos editores de Grandeza mexicana tienen sus propias propuestas de lectura: contentémonos con un par entre las más recientes: para José Carlos González Boixo, el interés de Balbuena es meramente individual; con la publicación de una obra escrita en 1602, el autor buscaba en 1604 «la proyección social» que había de servirle "para alcanzar las dignidades eclesiásticas que ansiaba» ${ }^{8}$, objetivo que comparte subsidiariamente Asima F. X. Saad de Maura para quien la cifra de Grandeza mexicana estriba más bien en su estatus de geografía letrada trasatlántica para "glorificar todo lo que proviene de España en un afán desbocado por revivir el poder imperial ya decadente.»" Por otra parte, en una nota sustancial de esta edición se afirma que lo que «la obra de Balbuena «esconde, o al menos obvia» es «la brutal realidad de su presente y los ochenta y pico de ańos precedentes» ${ }^{10}$.

En un artículo publicado en 2009, Barbara Fuchs y Yolanda MartínezSan Miguel habían puesto de manifiesto el «circuito trasatlántico de lectura, identificado con los centros de poder eclesiástico en México y monárquico en España.» ${ }^{11}$ Balbuena plasmará su anhelo en las dos dedicatorias de la doble edición de 1604, la una publicada por Melchior Ocharte, al Arzobispo de México y la otra salida de la imprenta de Diego López Dávalos, al Conde de Lemos. Pero, en mi opinión, lo fundamental de ese estudio es el acento puesto en la dimensión económica de la «nueva epopeya mercantil» de Balbuena. La recapitulación de las riquezas de la metrópolis colonial se convierte en el epílogo del poema «en una notable celebración de la autosuficiencia mercantil e institucional del centro virreinal americano, que se elabora en 92 de los 126

\footnotetext{
5. Paz (1965: 14).

6. Roggiano (1982: 270), quien subraya la palabra componer.

7. Gómez (2003: 531-532).

8. Balbuena (1988: 21).

9. Balbuena (2011: 26).

10. Balbuena (2011: 234, nota 265).

11. Fuchs y Martínez-San Miguel (2009: 677, nota 3).
} 
tercetos del capítulo final del poema ${ }^{12}$. España sólo entra en este resumen por medio de su relación económica con México [...]» ${ }^{13}$.

Las dos estudiosas siguen la pista del reconocido mexicanista francés Serge Gruzinski, quien además de ofrecerles el epígrafe de su trabajo, hizo de Grandeza mexicana el hilo de Ariadna de un libro modélico, citando abundantemente los versos de Balbuena a lo largo y ancho de Les quatre parties du monde. Histoire d'une mondialisation: "México aparece en el mismo corazón de redes mercantiles que abarcan el planeta. [...] Esta nueva geografía que sitúa a México en la línea divisoria del mundo es portadora de riquezas infinitas. Los tesoros de Oriente y de Occidente convergen hacia la ciudad para asegurarle lujo y prosperidad. ${ }^{14}$ Gruzinski parece glosar el soneto de alabanza a la obra de Don Lorenzo Ugarte de los Ríos, Alguacil mayor del Santo Oficio de la Inquisición en Nueva España: «Sea México común patria y posada, / de España erario, centro del gran mundo». ${ }^{15}$ El oficial de la Santa Inquisición da cuenta, como el mismo Balbuena, de un desplazamiento trasatlántico que hace de la Península la periferia de México, fuente de las riquezas de la «vieja» España. ¿Cómo este nuevo "centro del gran mundo" no podría ejercer una fuerza centrípeta que atrajera a los desplazados del antiguo eje? Más vale encontrarse cerca de la fuente del oro americano que de su puerto de llegada... ipor si acaso llega!

La cifra de Grandeza mexicana sería, pues, según Gruzinski, la primera globalización administrada por la Monarquía española entre los siglos XVI y XVII: «La descripción hiperbólica [de la circulación interoceánica de mercancías] hace que algunos pasajes de Grandeza mexicana se asemejen a un catálogo de tienda de lujo para fiestas de fin de año. [...] México es el almacén donde se amontona lo más refinado y exquisito del mundo.» ${ }^{16} \mathrm{El}$ deje irónico de Gruzinski resulta probablemente de los procedimientos enumerativos, tono grandilocuente y redundancias pleonásticas que, si bien los miramos, pertenecen precisamente a la clase de discurso cifrado que nos conviene ahora precisar.

Como primer paso nos detendremos algo en el dedicatario de la edición de Dávalos de Grandeza mexicana, el Conde de Lemos, también objeto de un «elogio» en versos un tanto rimbombantes («Nuevo Mecenas, gloria de la

12. A la verdad dicho capítulo, como los ocho anteriores, consta de tercetos (aquí 125) y de una cuarteta final (estrofa 126). Otro lunar de ese artículo es presentar Grandeza mexicana como destinada a una lectora metropolitana, "quien está a punto de emprender el viaje de Europa a América» (p. 676), mientras los biógrafos de dońa Isabel de Tobar y Guzmán y el mismo Bernardo de Balbuena señalan que Grandeza mexicana nació del deseo de doña Isabel, una criolla viuda, de informarse sobre "las grandezas y admirables partes de esta insigne y poderosa ciudad de México» (Balbuena 2011: 163) antes de ingresar a un convento de la capital virreinal dejando su lugar de residencia de San Miguel de Culiacán (Nueva Galicia, actualmente Sinaloa).

13. Fuchs y Martínez-San Miguel (2009: 690).

14. Gruzinski (2004: 103). Las traducciones del libro de Gruzinski son mías (véase también la traducción publicada en México, Fondo de Cultura Económica, 2010).

15. Balbuena (2011: 95).

16. Gruzinski (2004: 43). 
casa / más noble y más antigua / que España en sus Archivos atestigua [...]» ${ }^{17}$ ) añadido en un pliego de esta edición. Lejos de ser «un tributo apresurado» ${ }^{18}$ al todopoderoso Presidente del Real Consejo de Indias, o «una composición de circunstancias, puramente ocasional $»^{19}$, la canción ditirámbica, que desdobla ampulosamente la dedicatoria, quiere alcanzar al que más podía favorecer y acrecentar la grandeza mexicana bajo la presión de otros posibles lectores de la edición de Dávalos, los funcionarios del Consejo de Indias ${ }^{20}$.

La destinataria de la carta corográfica de Balbuena, doña Isabel de Tobar y Guzmán, tampoco es inocua: por su bisabuela era «parienta muy conocida y cercana del gran duque de Lerma don Francisco Gómez de Sandoval, que hoy es la persona más propincua a la de nuestro glorioso y católico monarca Filipo tercero ${ }^{21}$, como no deja de recordarlo nuestro autor al final de una «Introducción» en prosa que precede el «Argumento» y vuelve a redundar poéticamente la indirecta al principio del primer capítulo:

De Tobar y Guzmán hecho un injerto

al Sandoval, que hoy sirve de columna

al gran peso del mundo y su concierto. (I, 9, 166)

Quien está en la mira de Balbuena es nada menos que el valido del rey, pariente lejano de Doña Isabel. Tanto el Conde de Lemos, a quien por motivos también interesados Cervantes iba a dedicar Las novelas ejemplares y la Segunda Parte del Quijote, como el Duque de Lerma, por el poder conquistado en la Corte, constituían el primer círculo de lectores españoles capaz de tener un influjo decisivo desde el centro de la Monarquía sobre la administración del Mundo Nuevo en general y de México en particular, el lugar del Imperio más querido por Bernardo de Balbuena al redactar su Grandeza mexicana en 1602. A tales "protectores» hiperbólicamente alabados conviene una corografía fundamentada en un incesante tráfico de gentes y cosas que haga deseable vivir en «la mejor ciudad del mundo $»^{22}$ :

Recuas, carros, carretas, carretones,

de plata, oro, riquezas, bastimentos

cargados salen, y entran a montones (I, 38, 169)

Si de los preliminares y primeros versos nos transportamos a los versos finales (93-126) de la obra, volvemos a topar con el mismo círculo por medio de la alegoría de una Espańa interpelada en un largo vocativo:

¡Oh España valerosa, coronada

por monarca del viejo y nuevo mundo,

de aquél temida, deste tributada! (IX, 93, 246)

17. Balbuena (2011: 80).

18. Balbuena (1930: 120).

19. Rojas Garcidueñas (1958: 174).

20. Rojas Garcidueñas (1958: 117).

21. Balbuena (2011: 164).

22. Último octosílabo del poema de Francisco de Balbuena Estrada, hermano del autor, alabando Grandeza mexicana (Balbuena 2011: 102). 
La Espańa dominadora de ambos mundos debe su fuerza a la economía y comercio del nuevo, advierte Balbuena, que acaba de mostrar y demostrar que México es la «protagonista de una epopeya mercantil de la temprana modernidad $\aleph^{23}$ en la que el hombre de negocio ha sustituido al conquistador de los años 1520-1530, heredero del caballero de la Reconquista ${ }^{24}$.

A esos lectores peninsulares que detentan el poder de organizar política, económica y socialmente la primera globalización ibérica, Balbuena les había llamado la atención sobre cada uno de los elementos constitutivos del "Argumento», listos para generar más acumulaciones léxicas en los nueve "cantos» que siguen:
De la famosa México el asiento, origen y grandeza de edificios, caballos, calles, trato, cumplimiento, letras, virtudes, variedad de oficios, regalos, ocasiones de contento, primavera inmortal y sus indicios, gobierno ilustre, religión y Estado ${ }^{25}$.

No olvido que Grandeza mexicana, publicada dos veces en México, se dirigía también a un público criollo, o bien desparramado por el inmenso territorio de la Nueva España pero desconocedor de su centro, público de quien dońa Isabel de Tobar y Guzmán sería la figura metonímica, o bien vecino del nuevo eje del mundo («México al mundo por igual divide», III, 56a, 189), que necesitaba reforzar su orgullo de pertenecer a una comunidad que puede rivalizar con la misma Roma: ¿no se merece el primer dedicatario, Fray García de Mendoza y Zúníga, Arzobispo de México, vestir «la corona y la mitra de la suprema dignidad de [la Iglesia Católica], que es el Pontífice Romano»?26 ¿No debía el triunfalismo de Balbuena contrarrestar el testimonio deletéreo de un Baltasar Dorantes de Carranza, quien reparte el mismo año de publicación de Grandeza mexicana una Sumaria relación de las cosas de la Nueva España (1604) donde, en palabras de Serge Gruzinski, «se evoca a un México bien diferente, el de los advenedizos y de los timadores" y cuyo autor "padece en carne propia las desgracias de la Nueva Espańa»?27 Dorantes de Carranza regalaba argumentos a los que desde Madrid se hubieran atrevido a desmontar el panegírico de Balbuena y la causa que defendía con toda la alacridad de que era capaz. Balbuena encendía un imponente contrafuego a los detractores de México.

Pues todo nos inclina en creer que el público anhelado por Balbuena era el de la Península, desconocedor de visu de la grandeza mexicana y depositario de un poder de decisión, público elitista sí pero no el exclusivamente americano

23. Fuchs y Martínez-San Miguel (2009: 677).

24. Adorno (1989: 218).

25. Balbuena (1988: 37) cuya puntuación es preferible a Balbuena (2011: 164) aunque dejaría el punto después de "Estado» de la edición de Saad Maura en vez de la coma en la de González Boixo.

26. Balbuena (2011: 122).

27. Gruzinski (2004: 278). 
que se regodeara con los intríngulis manieristas destinados «a los deleites de sociabilidad de ciertos sectores hispanohablantes novohispanos. ${ }^{28}{ }_{¿}$ No serían más bien esos lectores los «discretos» españoles administradores del Imperio, a los que alude Balbuena en la por lo demás obligatoria dedicatoria «al lector» de un libro de la época? «[...] así como no es posible que este mi libro sea para todos, así tampoco lo es que deje de ser para algunos ${ }^{29}$ ? Y por si quedara alguna duda, Balbuena termina su erudita glosa a los versos dirigidos al Doctor Don Antonio de Ávila y Cadena, Arcediano de la Nueva Galicia (a la verdad en honor al Arzobispo de México) con una confesión no cifrada: «Y así los demás trabajos míos si algún día, como estos merecieren salir a luz, será gozando de las comodidades de España, enviándolos allá o disponiéndome yo a llevarlos.» ${ }^{30}$ No hay vuelta de hoja: el público elitista soñado de Grandeza mexicana, obra de encargo de la criolla doña Isabel de Tobar y Guzmán, nunca olvidada como destinataria de la carta («Aquí, señora, el cielo de su mano / parece que escogió huertos pensiles», VI, Gab, 210) ${ }^{31}$, está al otro lado del océano. La «cifra» de la que comisionó Grandeza mexicana es el habitante de la Península.

De España también le vendrían a Balbuena los premios individuales de un concepto utilitario de «la literatura como medio de elevación social »" que logró, también con el Siglo de oro en las selvas de Erifile (1608), otra vez dedicado al Conde de Lemos, siendo nombrado abad de Jamaica en 1608 y obispo de Puerto Rico en 1619.

Pero la alabanza tópico de una ciudad, aquí la de México, modalidad del género corográfico, tiene un alcance más amplio que el meramente descriptivo sobre todo cuando su «característica más sobresaliente: la acumulación de imágenes y objetos " ${ }^{33}, \tan$ propia del estilo barroco y su horror vacui, entraña por analogía otra clase de acumulación, la capitalista, resultado de la globalización ibérica de la que México es el «almacén» repletísimo:

con todos se contrata y se cartea,

y a sus tiendas, bodegas y almacenes

lo mejor destos mundos acarrea. (III, 60, 189)

¿De qué sirve ese discurso colmado de enumeraciones y señales de riquezas desbordantes escrito por un peninsular llegado a México de adulto (hacia los veintidós años) y "casado con los ideales imperiales»" ${ }^{34}$ si no es para persuadir a sus interlocutores pudientes del otro lado del Atlántico que la Nueva España es la tierra prometida con capacidad de acoger a más vecinos venidos antes que nada de las Españas? ¿Tiene otro propósito aquella diatriba (poco cristiana)

28. Gómez (2003: 538).

29. Balbuena (2011: 92).

30. Balbuena (2011: 159).

31. Véanse también Balbuena (2011, VII, 23a, 220; VII, 62b, 224; ; VIII, 21, 228; VIII, 38 43, 230-231; VIII, 69, 233; IX, 8a, 235).

32. Balbuena (1988: 22).

33. Balbuena (1988: 24).

34. Balbuena (2011: 13). 
contra la pobreza que Balbuena desencadena en su discurso preliminar al Arcediano de la Nueva Galicia?

Llamé indigna la pobreza por parecerme que es a la que sola en el mundo falta dignidad y estado. Varrón dice que dives se deriva de divus, y que así es lo mismo decir rico que divino, pues si lo que es divino merece suma reverencia, el pobre está al otro extremo, al ángulo contrario, por fuerza se ha de quedar indigno de toda estimación y respeto ${ }^{35}$.

Si rico vale divino, nos las habemos con la cifra de la riqueza que aplicada al conjunto de Grandeza mexicana hace de México una ciudad tan rica como divina, es decir atractiva por partida doble. De tal forma que al dirigirse a dońa Isabel de Tobar y Guzmán al umbral de la primera hilera de tercetos, Balbuena le abre a la vez las puertas del emporio del mundo y del convento donde quiere ingresar:

Oye un rato, señora, a quien desea aficionarte a la ciudad más rica, que el mundo goza en cuanto el sol rodea. (I, 5, 166)

$\mathrm{Y}$ al concluir el primer capítulo con una cuarteta cuya última palabra es «rica», el poeta otorga a la ciudad un aura divina resaltada por la posición estratégica al final absoluto de la última estrofa del capítulo de apertura:

Y así cuanto el ingenio humano fragua,

alcanza el arte y el deseo platica

en ella y su laguna se desagua

y la vuelve agradable, ilustre y rica. (I, 71, 173)

Pero también podemos pensar en un proceso subliminal de propaganda económica destinada a los pobres de fuera que en México dejarían de ser indignos ya que

La pobreza doquiera es vieja en cueros,

abominable, congojosa y fiera,

de mala cara y de peores fueros;

y aunque es bueno ser rico dondequiera,

lugares hay tan pobres y mendigos

que en ellos serlo o no es de una manera. (IV, 37-38, 195) $)^{36}$

Y México no es de aquellos lugares donde el rico sigue siendo pobre sino que a ella

Ríndase el mundo, ofrézcale la palma,

confiese que es la flor de las ciudades,

golfo de bienes y de males calma. (IV, 59, 198)

¿No querrá Balbuena inducir en sus lectores españoles del círculo más próximo al monarca la visión de un opulento nuevo centro del mundo que no conoce la

35. Balbuena (2011: 128).

36. Prefiero la puntuación de Balbuena (1988: 70) con el punto y coma al final del terceto 37, pero el punto después de "manera» (terceto 38) de Balbuena (2011) parece más lógico que la coma que pone González Boixo. 
pobreza, aquella «vieja en cueros», donde los indigentes de la Península dejarían de serlo? A esos miserables, Balbuena, mediante sus "protectores», les invita a cruzar el charco para establecerse en el «golfo de bienes» que es México. Y no sólo ellos sino todos los sujetos más emprendedores del Imperio que trabajan en condiciones pésimas ahí donde están. Definitivamente, México es la parte de la Monarquía donde mejor pueden esmerarse los artesanos:

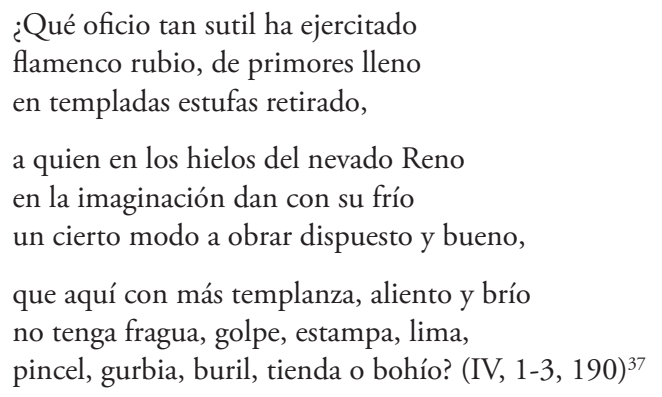

Esos invitados a compartir de 1604 en adelante las riquezas mexicanas se pondrían en los pasos de los conquistadores de 1521 impulsados por «la dulce golosina» del «interés» (II, 5, 175) es decir según la definición unívoca de Covarrubias «el provecho, la utilidad, la ganancia que se saca o espera de una $\cos a{ }^{38}$, el motor de todas las cosas, como lo machaca y vuelve a machacar el cantor de las grandezas mexicanas:

$\mathrm{Y}$ así vuelvo a decir y otra vez digo

que el interés, señor de las naciones,

del trato humano el principal postigo. (II, 22, 177)

El trato, o sea los negocios ${ }^{39}$, que encuentra en México su conclusión, sobrepasando el comercio de Troya y de Roma en la Antigüedad así como el más reciente de Venecia, y que llegado allí "por pasos diferentes / está en la mayor cumbre de grandeza / que vieron los pasados y los presentes.» (II, 29, 178) El pensamiento mercantil embebe la corografía de Balbuena que por hiperbólica que sea no deja de ser económica:

Pues de su plaza el tráfago y concurso,

lo que en ella se vende y se contrata,

¿en qué suma cabrá o en qué discurso? (IV, 22, 193)

Por si fuera poco, volviendo a evocar la equivalencia entre riqueza y divinidad, Balbuena exalta el lugar

Donde si el mundo en su mortal tesoro

puede contrahacer sombras de cielo,

al vivo vive ahí el celestial coro. (II, 41, 179)

37. Aquí también prefiero la puntuación de González Boixo para el $2^{\circ}$ verso de IV, 1 (Balbuena 1988: 65).

38. Covarrubias (2006: s.v.).

39. Véase Covarrubias (2006: s. v. «Tratar»). 
Y para coronar el segundo capítulo de la obra, el poeta no teme las hipérboles más atrevidas:

templo de la beldad, alma del gusto,

Indias del mundo, cielo de la tierra;

todo esto es sombra tuya ¡oh pueblo augusto!

y si hay más que esto, aun más en ti se encierra. (II, 57, 181) ${ }^{40}$

Hablando de figuras retóricas, con la acumulación anafórica «casas, calles, caballos, caballeros» (III, 8b, 183), eco de la anterior «Recuas, carros, carretas, carretones» (I, 38a), nos las habemos con un proceso que anestesia la razón del lector preparándole a otra enumeración capitalista en el sentido más elemental de la palabra a la vez que propia del discurso propagandístico:

Ricos jaeces de libreas costosas

de aljófar, perlas, oro y pedrería,

son en sus plazas ordinarias cosas. (III, 10, 183)

Un terceto, si se me permite la expresión, que llueve sobre mojado: los brillantes y costosos ornamentos se sobreponen a lo que ya era en sí una señal de poder, el caballo.

La opulencia de la ciudad, metonimia de la primera globalización, se traduce aquí en enumeraciones de riquezas ("Al fin, del mundo lo mejor, la nata / de cuanto se conoce y se practica, / aquí se bulle, vende y se barata.») (III, $46,188)$ que han de producir el mismo efecto hipnótico que, por ejemplo el "vertiginoso ${ }^{41}$ catálogo de plantas, flores, árboles, ríos, ninfas y animales de que goza la primavera mexicana (VI, 7-60, 210-216): así abrumado por tanto léxico exuberante el lector aceptará el contenido de Grandeza mexicana, que se confunde con un discurso propagandístico cuyo destinatario final se adivina «cifrado» en la apóstrofe:

¡Oh pueblo ilustre y rico en quien se pierde

el deseo de más mundo, que es muy justo

que el que éste goza de otro no se acuerde! (III, 29, 186)

¿No será ese «otro mundo» el Viejo, el de la Península y de las posesiones europeas de la Monarquía espańola, que en México se olvida por ser su «pueblo ilustre y rico», además de ser pródigo y generoso («aquel pródigamente darlo todo, / sin reparar en gastos excesivos») (III, 34, 186)? La riqueza de la Nueva España es fuente de virtud, proclama el capítulo III cuyo último verso, verdadera puesta en abismo del canto y de la obra da sin cansarse en el mismo clavo de la repetición, proceso didáctico...y propagandístico por excelencia: «ciudad ilustre, rica y populosa.» (III, 61d)

Nada mejor para encomiar la Grandeza mexicana que dar cuenta de la experiencia personal que aquí deja la grandilocuencia por una llaneza casi tierna: «que yo en México estoy a mi contento» (IV, 58a, 197). ¿Quién no? A

40. Sigo aquí el texto de Balbuena (1988: 54) por la puntuación propuesta por González Boixo.

41. El adjetivo muy acertado es de Saad Maura en Balbuena (2011: 212, nota 233). 
los encantos naturales de la ciudad se agregan los del espíritu, el culto de las letras humanas y divinas así como los socorros más selectos de la religión (IV, 60-81). Hasta harán su agosto los hombres sensibles a las cualidades de las damas las cuales, inútil decirlo, tienen todas la «cumplida perfección» que de un lugar paradisíaco se espera (V, 24-29, 204).

No se me escapó el adjetivo por casualidad: en la «primavera inmortal ('eterna')», es decir «en este paraíso mexicano / su asiento y corte la frescura ha puesto.» (VI, 5bc, 210) El paraíso terrestre junto con la divinidad de las riquezas mexicanas es una cifra más de la obra en tanto es sombra del otro, el del reino de Dios. Y ya que de cifra seguimos tratando, el clásico valle griego de Tempe, entre el Osa y el Olimpo, aunque grandioso, era sólo un «indicio», una «reducción», una pálida «abreviación» del de México a principios del siglo XVII:

Bellísimo sin duda es este llano,

y aunque lo es mucho, es cifra, es suma, es tilde

del florido contorno mexicano. (VI, 18, 211) ${ }^{42}$

Volviendo a la tierra y al gobierno «del mundo nuevo la primera silla» (VII, 3c, 217), administrado con sabiduría por los virreyes de la Nueva España que se sucedieron desde Antonio de Mendoza (1535-1550) hasta el que otorgó la licencia de impresión de Grandeza mexicana ${ }^{43}$, Gaspar de Zúńiga y Acevedo, Conde de Monterrey (1595-1603) (VII, 13-18, 218-219), quienquiera llegara del Viejo mundo no dejaría de asombrarse de la paz y seguridad de la ciudad, condiciones imprescindibles para que vengan a acrecentar su población los demás súbditos del Imperio. Estos estarían también en condición de constatar que los dos motivos principales que justificaron la conquista, la difusión de la religión cristiana y la búsqueda del oro, se estrechan apretadamente a tal punto que el segundo término de metáforas y comparaciones relativas al campo religioso remite a las riquezas de México. Así las múltiples órdenes religiosas instaladas ahí son "pedrería a sus engastes de oro" (VIII, 12c, 226) y las monjas del convento de San Juan Bautista imitando «la aspereza» del que bautizó a Cristo "cual oro en el crisol se afinan» (VIII, 46bc, 231). En el de Regina, "nacieron / riqueza y santidad en una cara» (VIII, 31ab, 229), o sea en una yuxtaposición verbal que hace indisoluble la una, terrestre, y la otra, celestial.

En fin de cuentas los hombres y las mujeres que desde otras partes del Imperio quisiesen ingresar en la Iglesia encontrarán las mejores condiciones en México, que hasta «nueva Roma parece en trato y talle» (VIII, 64c, 233).

Pero si otra vez es el «interés» el que arrastra al emigrante y tiene algún dinero, que lo invierta en la compra de casas en esta ciudad

donde hay alguna en ellas tan altiva, que importa de alquiler más que un condado, pues da de treinta mil pesos arriba. (IX, 20, 237)

42. Véanse las definiciones de suma y tilde en Covarrubias (2006: s. v.) que remiten respectivamente a los conceptos de 'reducción' y 'abreviación'.

43. Balbuena (2011: 93). 
Las treinta y cuatro últimas estrofas de Grandeza mexicana, como vimos, interpelan a España, beneficiaria principal de las riquezas de su colonia y del oro que le manda continuamente. Pero se sobrentiende que la Nueva España necesita de pobladores para proveer a tope de materias y metales preciosos las flotas que volverán a cruzar el océano hacia la madre patria, la cual, a su vez, como centro, pero ahora centro secundario, de la globalización ibérica repartirá las riquezas mexicanas por todos los territorios del Imperio. De hecho la verdadera entidad reguladora de la nueva economía es «la Caja real, pilar deste edificio / Casa de fundición y de moneda» (IX, 75ab) ${ }^{44}$ cuya sede está en la ciudad de México.

Los curiosos lectores que seguirán hojeando el volumen de Grandeza mexicana toparán con un Compendio apologético en alabanza de la Poesía en una prosa erudita algo farragosa. En realidad es una nueva "cifra» en defensa de la obra anterior, en relación directa, pues, con ella, lo que, al parecer José González Boixo no vio. ${ }^{45}$ Por lo tanto merecen citarse alguna que otra frase de las dos últimas páginas del Compendio.

\footnotetext{
[La poesía] que aquí escribo - reconoce - no es del todo divina, es a lo menos honesta y grave, y en el sujeto, heroica, y no por términos del todo humildes ni fuera de las leyes y condiciones del arte [...].

Mas ahora basta para recomendación destos breves discursos y de los escrúpulos que han reparado en ellos, que no son en el sujeto tan humildes y caídos que no traten las grandezas de una ciudad ilustre, cabeza y corona destos mundos occidentales [...] y digna por las grandes partes que en ella concurren de ser celebrada por casi única y sola.
}

Y por si alguien no hubiera entendido, Balbuena vuelve a definir Grandeza mexicana: «De manera que mi poesía, en estilo heroico y grave, trata de la más noble, de la más rica y populosa ciudad desta nueva América [...].» ${ }^{46}$

Antes que nada el propio autor justifica de antemano a los comentaristas que tildaron Grandeza mexicana de "épica urbana» o de "epopeya mercantil», género en los cuales el héroe individual de la épica clásica ha sido desplazado por una corografía económica poniéndose bajo la tutela de Homero y Virgilio, mencionados en el cuerpo de la obra en verso aunque sea bajo la reserva del topos de la ineludible humildad:

Hazañas dignas del caudal de Homero

en el mío mal pueden ajustarse,

sin mucho agravio de su noble fuero. (VIII, 59, 232) (77 $^{4}$

Sujeto y estilo heroico corresponden a lo que se espera de una épica salida de la pluma de un fiel y sometido súbdito de una España, donde quiere morirse

44. La mayúscula de «Casa de fundición» de Balbuena (1988: 117) nos parece más correcta que la minúscula de nuestra edición de referencia.

45. Balbuena (1988: 23).

46. Balbuena (2011: 275-276).

47. Véanse también las menciones de «el grave Homero, el claro y el sencillo / Virgilio» (Balbuena 2011: IX, 54, 241). 
o, por lo menos, donde desea que lo entierren ${ }^{48}$ lo que el destino, que le fue tan propicio en vida, no quiso cumplir después de muerto: Bernardo de Balbuena terminará sus días en San Juan de Puerto Rico en cuya catedral yacen su «humilde cuerpo» y «cenizas».

Esa epopeya ditirámbica de la Nueva España es también utópica con toda la fuerza atractiva de una Utopía ${ }^{49}$ que está, por así decirlo, a la mano de los habitantes de las posesiones europeas de la Monarquía española. Balbuena reinterpreta la realidad mexicana desde su formación intelectual peninsular y los aires utópicos que soplaban a la vuelta de los siglos XVI y XVII. Lo que estamos leyendo es una guía turística de propaganda escrita a la luz de una poética utópica de propósitos altamente prácticos. Los tiempos que vivía el imperio globalizado de Felipe III necesitaban la voz exaltada de un Balbuena para que la cúpula de la Monarquía promoviera una política de emigración de la Península a la Nueva España. Grandeza mexicana es un poco más que un mapa que recorrerían pasivamente «los lectores que se quedaron allá, al otro lado del Atlántico. ${ }^{50}$ Su función es la de movilizar su curiosidad, la de los dirigentes y funcionarios de la Corte capaces políticamente de arrancar del Viejo Mundo los que se animarían a gozar de las maravillas y riquezas del Nuevo. ¡Buena falta les hacía al gobierno y administración de España para que despachasen el documento oficial a los que solicitaban el permiso de cruzar el Atlántico, es decir de participar en la globalización en su centro desplazado de Madrid a México! Recuérdense las negativas que sufrió Cervantes para juntarse a los que querían medrar en América.

En un último escrúpulo y duda sobre la perennidad de los bienes materiales, Balbuena cita de Ovidio la décima elegía del primer libro en los renglones finales de su Compendio apologético en alabanza de la Poesía:

Todo se acabará con los diversos cursos del tiempo: el oro, los vestidos, las joyas y tesoros más válidos, y no el nombre inmortal que dan los versos. ${ }^{51}$

El último verso, que también es el de la obra y de su complemento, es indudablemente el que más cuenta para Balbuena: él es este poeta de «nombre inmortal» y los versos de Grandeza mexicana se leerán por los siglos de los siglos «cifrando» este su Siglo de oro en la Nueva España, que fue algún tiempo el centro del mundo y el imán donde debían de pegarse los emigrados de los territorios europeos del Imperio animados por los lectores naturales y selectos de la obra.

48. «[...] a tus playas / mi humilde cuerpo vuelva, o sus cenizas.» (Balbuena 2011: IX, 123, 249)

49. Véase Torres (1998).

50. Saad Maura en Balbuena (2011: 58).

51. Balbuena (2011: 276). 


\section{Bibliografía}

Adorno Rolena, «Arms, Letters and the Native Historian in Early Colonial Mexico», en R. Jara y N. Spadaccini (eds.), Re/Discovering: 1492-1992: Re/DiscoveringColonial Writing, Hispanic Issues, IV, Minneapolis, University of Minnesota Press, 1989, pp. 202-224.

Balbuena Bernardo de, Grandeza mexicana, ed. J. Van Horne, Urbana, University of Illinois, 1930.

- Grandeza mexicana, ed. L. A. Domínguez, México, Porrúa, 1971.

- Grandeza mexicana, ed. J. C. González Boixo, Roma, Bulzoni, 1988.

- Grandeza mexicana, ed. A. F. X. Saad Maura, Madrid, Cátedra, «Letras Hispánicas, 688», 2011.

Covarrubias Horozco Sebastián de, Tesoro de la lengua castellana o española, ed. I. Arellano y R. Zafra, Madrid/Frankfurt, Iberoamericana/Vervuert, 2006.

Fuchs Barbara y Martínez-San Miguel Yolanda(2009), « La Grandeza mexicana de Balbuena y el imaginario de una 'metrópolis colonial », Revista iberoamericana, 1989, LXXXV, pp. 675-695,

Gómez Fernando, « Estética manierista en los albores de la periferia colonial americana. Acerca de la Grandeza mexicana de Bernardo de Balbuena (1562-1627) », Hispanic Review, 2003, LXXI, pp. 525-548.

Gruzinski Serge, Les quatre parties du monde. Histoire d'une mondialisation, París, Éditions de La Martinière, 2004.

Paz Octavio, Las peras del olmo, México, Universidad Nacional Autónoma de México, 1965 (2a ed.).

Rojas Garcidueñas José, Bernardo de Balbuena, México, Universidad Nacional Autónoma de México, « Instituto de Investigaciones Estéticas», 1958.

Roggiano Alfredo A, (1982) «Bernardo de Balbuena», en Historia de la literatura Hispanoamericana. Época colonial, L. I. Madrigal (ed.), Madrid, Cátedra, pp. 215224.

Torres David, « De la utopía poética en Grandeza mexicana de Bernardo de Balbuena», Caliope, 1998, IV, 86-93. 